\title{
General models of marine animal habitats require a process-based approach to parameter selection and model design
}

\author{
Henrik Skov ${ }^{1, *}$, Frank Thomsen ${ }^{2}$ \\ ${ }^{1}$ DHI, Agern Alle 5, 2970 Hørsholm, Denmark \\ ${ }^{2}$ Centre for Environment, Fisheries and Aquaculture Science, Pakefield Road, Lowestoft, Suffolk NR33 0HT, UK
}

\begin{abstract}
In Skov \& Thomsen (2008) we concluded-based on a novel, process-based approach - that the most important factor governing the distribution of harbour porpoises at Horns Reef, North Sea, is tidally-driven upwelling. In their Comment, Tougaard \& Wisz (2010, Mar Ecol Prog Ser 399:295-297) argue that the conclusion in Skov \& Thomsen (2008) was poorly founded by the analyses, due to inclusion of data collected during the construction of a wind farm, the selection of explanatory variables based on data dredging, and the lack of assessment of statistical uncertainty and model validation. We demonstrate that the selection of the data was not compromised, neither by the presence of wind farm construction activities, nor by the initial use of a large number of model parameters. The integrated application of hydrodynamic models, geo-statistics and partial least squares regression assured that model parameters were selected using an ecosystem-based approach. A formal internal validation of model performance using relative operator characteristics underlined the excellent robustness of our models, with AUC values $\geq 0.78$.
\end{abstract}

KEY WORDS: Spatial prediction models - Harbour porpoise - Ecosystem-based approach . Partial least squares regression

\section{Introduction}

The harbour porpoise Phocoena phocoena has recently become a focal species in marine management and conservation, e.g. in relation to the construction of offshore wind farms (Nedwell \& Howell 2004, Madsen et al. 2006, Thomsen et al. 2006, Tougaard et al. 2006) and the implementation of the EU Habitats Directive (EU 1992) According to Annex 2 in EU (1992), member states of the European Union are obligated to designate marine protected areas that provide physical and biological features essential to the life and reproduction of the species. Due to the limited knowledge of the habitat requirements of harbour porpoises in EU waters the implementation of the EU Habitats Directive has been incomplete for this spe- cies, and thus research to disentangle the key drivers for the distribution dynamics of harbor porpoises is much needed. Tougaard \& Wisz (2010, this volume) questioned our conclusion in Skov \& Thomsen (2008) of analyses of sightings and acoustic data from Horns Reef, North Sea, that the most important factor governing the distribution of harbour porpoises at this location is tidally-driven upwelling. The debate between Tougaard and Wisz and ourselves stems from opposing approaches to the selection of predictor variables and to the design and programming of marine habitat models.

Tougaard and Wisz argued that the conclusion was poorly founded by the analyses, due to inclusion of data collected during the construction of a wind farm, the selection of explanatory variables based on data 
dredging and the lack of assessment of statistical uncertainty and model validation.

\section{Data selection should be controlled by an ecosystem- and process-based approach}

The visual survey data used for the habitat models included results obtained on $2 \mathrm{~d}$ during the construction phase of the Horns Rev 1 offshore wind farm. On one of these days ramming of monopile foundations was undertaken. Tougaard and Wisz found that the previously documented behavioural responses of harbor porpoises to pile-driving would have made the data unrepresentative. However, the behavioural responses demonstrated by the same POD data (Tougaard et al. 2003, 2009) were shown to be shortterm ( 6 to $24 \mathrm{~h}$ ), and since surveys were chiefly undertaken between ramming periods, the distribution on at least 3 of the 4 periods selected can be considered as undisturbed, whereas the distribution during the 4 th period may have been moderately modified. Nevertheless, the distribution of sightings during northward and southward tidal currents during the 4 th period was similar to the distribution of the animals recorded during the other 3 periods, during which ramming activities did not take place.

Tougaard and Wisz stated that ecological theory to guide the selection of marine habitat parameters to harbour porpoises is limited. We claim that a great amount of scientific literature exists on spatial distribution of marine predators, with particular attention having been paid to scale-dependence of observed patterns (Schneider \& Piatt 1986, Russell et al. 1992, Fauchald 1999). The theory of hierarchical patch dynamics (Kotliar \& Wiens 1990) proposed an ecological framework to study the spatial distribution of animals, and the framework has been applied to marine predators (Fauchald et al. 2000, Certain et al. 2007). The history of marine mammal habitat modeling has shown the need to develop novel and more realistic habitat models based on an understanding of the scale-dependence of driving ecological processes (Gregr 2009). This point touches on the primary goal of our analyses: to derive a more realistic parameterization of habitat models for harbour porpoises and other marine animals. The robustness of habitat models is not only related to their statistical properties, but also to the ability of predictor variables and modeling scale to correctly describe the hierarchy of physical oceanographic processes that constitute the domain of habitats suitable to the target animals. Of course, habitat suitability should be evaluated in relation to the specific objectives of the management or conservation decisions that the model addresses. Attempts to develop realistic models of the fine-scale habitats of marine animals have often failed, not due to poor model performance but due to a lack of knowledge of the scale-dependence of habitat drivers, resulting in biased estimates of distribution patterns (Wiens 1989). This bias can, for instance, be identified by a poor match between the habitat identified as suitable by the model and the aggregative response by the animals shown in survey data; Tougaard et al. (2006) is an example of biased prediction models, in this case based on the same survey data as Skov \& Thomsen (2008). The latter focuses on scale-dependence of habitat drivers for harbour porpoises at one location in the North Sea; by integrating a long time series of parallel visual surveys, acoustic monitoring and hydrodynamic modeling Skov \& Thomsen (2008) demonstrated how a process-based approach can enhance both parameter selection and model design.

While focusing on model parsimony and performance, Tougaard and Wisz found that the spatial structure in the data as elucidated by the geo-statistical analysis calls for the development of a large-scale model. However, our application of geo-statistical analysis constitutes the initial step of the dynamic scale-dependent decomposition of the hydrodynamics around Horns Reef, a step which is a prerequisite for linking survey and acoustic data to the serial and spatial scales of structures and processes described by the hydrodynamic model. The method of linking dynamic model data to geo-statistical analyses is well established in marine ecology, and should be a fundamental property of all initial steps in developing marine habitat models (Guisan \& Thuiller 2005, Guisan et al. 2006). The method is not straightforward, as it requires detailed knowledge of the local and regional physical oceanography of the model area. Tougaard and Wisz found that the basis for the selection of model scenarios was unclear; however, as we stated in Skov \& Thomsen (2008), the selection is based on the criteria of large sample sizes (>100 porpoises observed) and temporal overlap between sightings and the different frontal positions of the large-scale density front off the Danish coast. During the 4 surveys selected, the position of the density front shifted in response to inflow of river water, and winds, among the western, southern, central, and eastern part of the Horns Reef Area. The position of the localized upwelling cells did not change with the position of the density front, however, and always coincided with areas where strong tidal currents were interacting with the steep topography of the reef - areas with a diameter $<10 \mathrm{~km}$, matching the aggregative response of the animals as given by the survey variograms (Fig. 1). It is correct that the available acoustic data had a coarser resolution than required to fully reflect the pattern of upwelling 

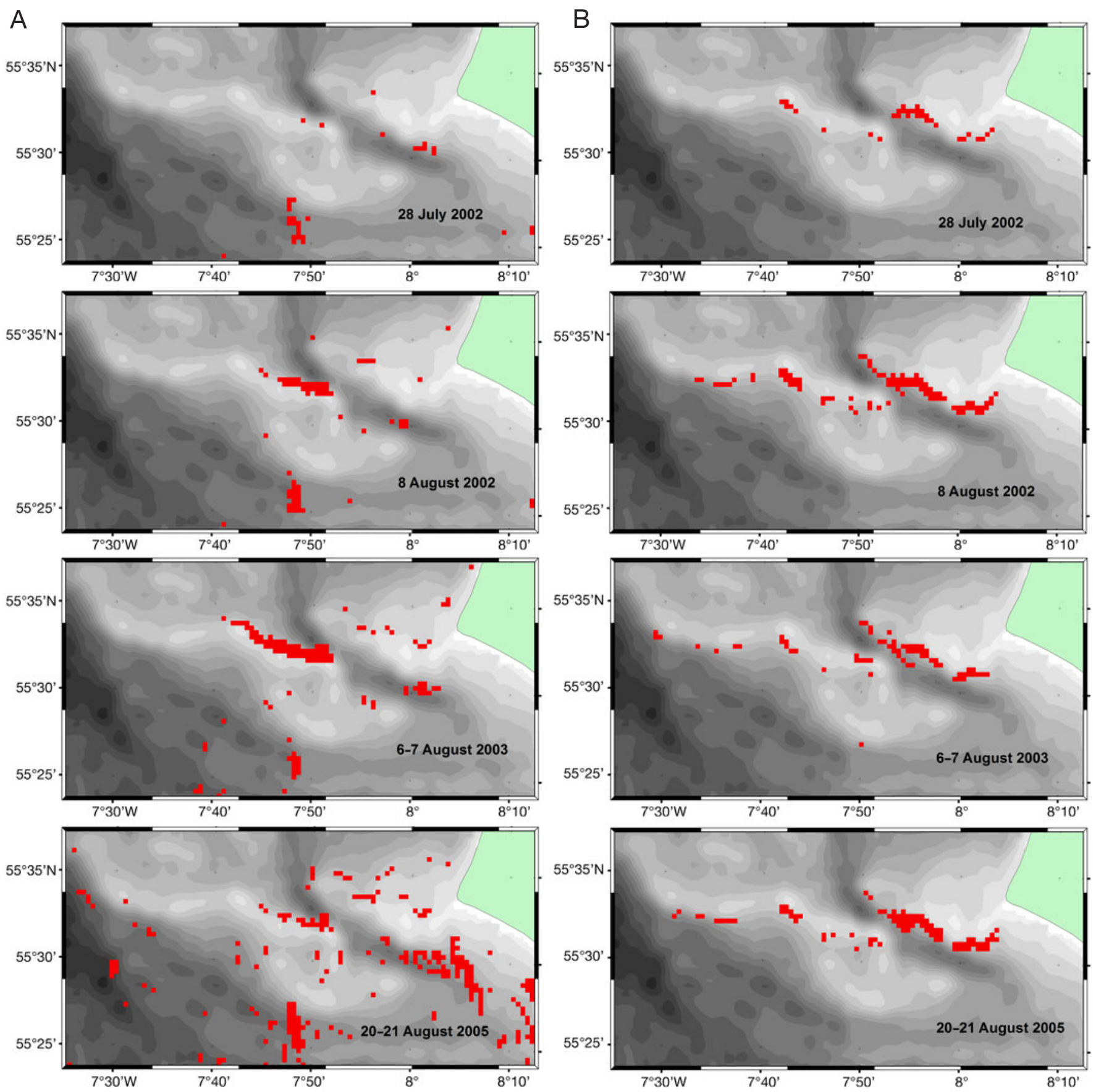

Fig. 1. Location of upwelling (red pixels) during (A) south-flowing and (B) north-flowing tidal currents in the 4 survey periods. Bathymetry ranges from 30 (dark grey areas) to $5 \mathrm{~m}$ water depth (white areas)

induced by the tidal excursion and, in fact, Skov \& Thomsen (2008) acknowledged this in the 'Discussion'. However, the daily click data still contained strong signals induced by the upwelling activity, as higher porpoise click rates were recorded by the T-PODs in proximity to the upwelling cells, as compared to the T-PODs located in regions of lower upwelling activity.

\section{Statistical tools avoid problems of spurious parameter selection}

According to Tougaard and Wisz, the selection of model parameters might have been the result of data dredging, which should be avoided as an initial or integrated step in parameter selection, as it often leads to 


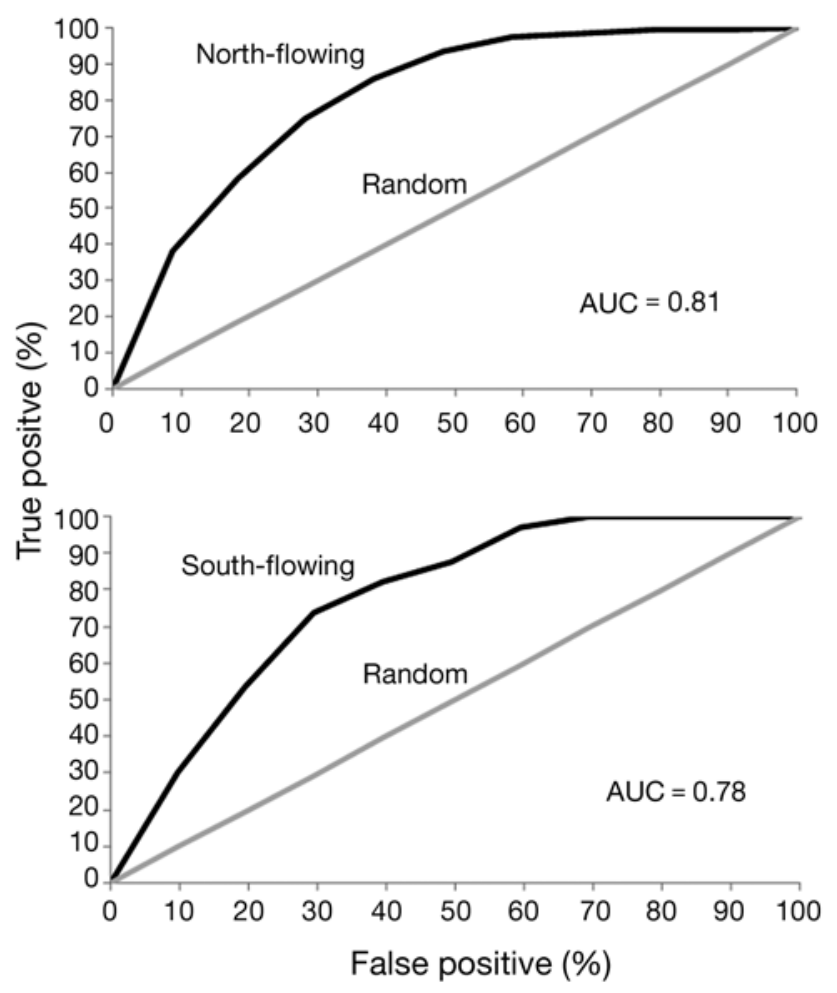

Fig. 2. Receiver operator characteristic statistics (Hosmer \& Lemeshow 2000) for the habitat suitability prediction models in Skov \& Thomsen (2008), covering north- and south-flowing tidal current scenarios

spurious or chance results. However, compared to multiple regression techniques, partial least squares (PLS) analyses have improved statistical properties for teasing out linkages between response variables and a large number of potential predictor variables, including better overall predictive performance and much lower sensitivity to the distribution of variable values, which for optimal performance in multiple regression need to be individually normal and mutually orthogonal. Most importantly, PLS displays a more conservative behaviour with a much lower probability of obtaining significant correlations through chance (Osborne et al. 1997, Weber et al. 2006). We specifically avoided problems of spurious parameter selection. PLS has not been widely used in habitat modeling, but it does have great potential for achieving better selection of habitat drivers than many other statistical methods.

\section{Ecological niche factor analysis (ENFA) and parsimony}

As outlined in Skov \& Thomsen (2008), the statistical performance of the harbour porpoise spatial model was not formally tested, i.e. spatial predictions were not val- idated against observations. Yet as can be seen from our results, the predictions were in agreement with the observed pattern of distribution and the acoustic data. These corresponding fine-scale patterns could never be a result of chance. A formal internal validation of model performance using Receiver operator characteristic statistics (Hosmer \& Lemeshow 2000) underlines the robustness of the model with AUC values $\geq 0.78$ for both tidal current scenarios (Fig. 2).

\section{Conclusion}

The process-based approach for fine-scale modeling of the habitat of harbour porpoises and other marine mammals should be evaluated using other data, and in other oceanographic regions. As the results of marine habitat modeling may have considerable importance for future management of the sea, marine habitat modeling must move towards achieving a high degree of spatial precision and a realistic display of distribution dynamics. We think that our harbour porpoise model for Horns Reef constitutes a promising step in this direction.

\section{LITERATURE CITED}

Certain G, Bellier E, Planque B, Bretagnolle V (2007) Characterising the temporal variability of the spatial distribution of animals: an application to seabirds at sea. Ecography 30:695-708

EU (European Union) (1992) Habitats Directive. Council Directive 92/43/EEC of 21 May 1992 on the conservation of natural habitats and of wild fauna and flora. Official Journal of the European Communities No. L206, 22-071992.

Fauchald P (1999) Foraging in a hierarchical patch system. Am Nat 153:603-613

Fauchald P, Erikstad KE, Skarsfjord H (2000) Scale-dependent predator-prey interactions: the hierarchical spatial distribution of seabirds and prey. Ecology 81:773-783

Gregr E (2009) Ecological modeling. In: Baumgartner M (ed) Proc 18th Biennial Conf Biology of Marine Mammals: Workshop on Ecological Modeling for Marine Mammalogists. Québec City, 12-16 October 2009

Guisan A, Thuiller W (2005) Predicting species distribution: offering more than simple habitat models. Ecol Lett 8: 993-1009

Guisan A, Lehman A, Ferrier S, Austin MP, Overton JMC, Aspinall R, Hastie T (2006) Making better biogeographical predictions of species' distributions. J Appl Ecol 43: 386-392

Hosmer DW, Lemeshow S (2000) Applied logistic regression, 2nd edn. Wiley-Interscience, New York

Kotliar NB, Wiens J (1990) Multiple scales of patchiness and patch structure: a hierarchical framework for the study of heterogeneity. Oikos 59:253-260

Madsen PT, Wahlberg M, Tougaard J, Lucke K, Tyack PL (2006) Wind turbine underwater noise and marine mammals: implications of current knowledge and data needs. 
Mar Ecol Prog Ser 309:279-295

Nedwell L, Howell D (2004) A review of offshore windfarm related underwater noise sources. SubAcoustics Rep No. 544 R 0308, October 2004, COWRIE, London

Osborne SD, Jordan RB, Kunnemeyer R (1997) Method of wavelength selection for partial least squares. Analyst (Lond) 122:1531-1537

Russell RW, Hunt GL Jr, Coyle OK, Cooney RT (1992) Foraging in a fractal environment: spatial patterns in a marine predator-prey system. Landscape Ecol 7:195-209

Schneider DC, Piatt JF (1986) Scale-dependent correlation of seabirds with schooling fish in a coastal ecosystem. Mar Ecol Prog Ser 32:237-246

Skov H, Thomsen F (2008) Resolving fine-scale spatio-temporal dynamics in the harbour porpoise Phocoena phocoena. Mar Ecol Prog Ser 373:173-186

Thomsen F, Lüdemann K, Kafemann R, Piper W (2006) Effects of offshore wind farm noise on marine mammals and fish. Report for COWRIE, London (available at: www. offshorewindfarms.co.uk)

Tougaard J, Wisz MS (2010) General models of the spatial distribution of porpoises require representative data and par-

Editorial responsibility: Matthias Seaman,

Oldendorf/Luhe, Germany simony: Comment on Skov \& Thomsen (2008). Mar Ecol Prog Ser 399:295-297

Tougaard J, Carstensen J, Henriksen OD, Skov H, Teilmann J (2003) Short-term effects of the construction of wind turbines on harbour porpoises at Horns Reef. Tech rep HME/362-02662 to Techwise A/S, Hedeselskabet, Roskilde

Tougaard J, Carstensen J, Wisz MS, Teilmann J, Bech NI, Skov H (2006) Harbour porpoises on Horns Reef — effects of the Horns Reef wind farm. Tech rep to Elsam Engineering A/S, National Environmental Research Institute, Roskilde

Tougaard J, Carstensen J, Teilmann J, Skov H, Rasmussen P (2009) Pile driving zone of responsiveness estends beyond $20 \mathrm{~km}$ for harbour porpoises (Phocoena phocoena (L.)). J Acoust Soc Am 126:11-14

Weber KC, Honorio KM, Bruni AT, Andricopulo AD, da Silva ABF (2006) A partial least squares regression study with antioxidant flavonoid compounds. Struct Chem 17: $307-313$

Wiens J (1989) Spatial scaling in ecology. Funct Ecol 3: 385-397

Submitted: December 18, 2009; Accepted: December 28, 2009 Proofs received from author(s): January 3, 2010 